\title{
A New Genus of the Actinomycetales: Microellobosporia gen.nov.
}

\author{
By T. CROSS \\ Department of Biological Sciences, Bradford Institute \\ of Technology, Bradford 7, \\ MARY P. LECHEVALIER AND H. LECHEVALIER \\ Institute of Microbiology, Rutgers, The State University, New Brunswick, \\ New Jersey, U.S.A. \\ SUMMARY \\ Two aerobic mesophilic species of a new genus belonging to the family \\ Actinoplanaceae are described under the name Microellobosporia ( $\boldsymbol{M}$. \\ cinerea type species). The new genus is characterized by the production of \\ small club-shaped sporangia on the aerial mycelium. Similar stuctures are \\ also formed on the substrate mycelium. The non-motile sporangiospores \\ are few in number and arranged in a single straight row inside the \\ sporangium.
}

\section{INTRODUCTION}

Since the publication of the 1957 edition of Bergey's Manual, Rothwell (1957) has published detailed studies on an organism, previously found by Karling (1954), which could be placed in the family Actinoplanaceae Couch. There has been some speculation as to the relationship between these 'Karling's organisms' and members of the genus Streptomyces (Hesseltine, 1960) following the work of several investigators on the mode of spore formation in this latter genus (Krassilnikov, 1949; Vernon, 1955; Glauert \& Hopwood, 1961). The present paper reports the isolation and description of three aerobic actinomycete strains which form sporangia containing one short single row of sporangiospores. The strains differ significantly from the previously described genera in the family Actinoplanaceae and it is proposed to include them in a new genus Microellobosporia, the type species being $M$. cinerea. A culture has been deposited in the culture collection of the Institute of Microbiology, Rutgers, The State University, New Brunswick, New Jersey (No. 3855) as well as two strains of a second species M. flavea (Nos. 3857 and 3858). Because no qualitative difference was found in the microscopic properties of these three strains, morphologic properties of members of this genus were illustrated when suitable, in Plate 1 with photographs of the strains of $M$. flavea.

\section{METHODS}

Isolation. Samples of soil, diluted in $\mathrm{pH} 7 \cdot 0$ phosphate buffer or tap water, were spread on tap-water agar, the defined agar medium of Lechevalier, Solotorovsky \& McDurmont (1961) or glucose asparagine agar (Waksman, 1950) and incubated at $\mathbf{2 6}^{\circ}$ or $\mathbf{3 6}^{\circ}$. Plates not overgrown with bacteria and fungi were examined at weekly intervals. 
Culture media. The isolates were subcultured onto slopes of potato + carrot agar, and freeze dried. The composition of the media used in their characterization and for which there is no reference in the text are given below.

Potato + carrot agar. Diced potato 150 g., diced carrot 30 g., tap water $1000 \mathrm{ml}$., steamed $30 \mathrm{~min}$., filtered, the volume adjusted to $1000 \mathrm{ml}$, agar $20 \mathrm{~g}$., pH 6.5.

Soya +glucose agar. Soya-bean meal $10 \mathrm{~g}$., glucose 10 g., $\mathrm{CaCO}_{3} \mathbf{0 . 7 5}$ g., water $250 \mathrm{ml}$., pH 5.5-5.8. Autoclave at $15 \mathrm{lb}$. for $15 \mathrm{~min}$., decant liquid and dilute $1 / 8$ with water. Adjust $\mathrm{pH}$ to $7 \cdot 9-8 \cdot 1$, add $17 \mathrm{~g}$. agar/l.

$X S M$ agar. Malt extract 1 g., yeast extract 1 g., liver extract 1 g., corn steep liquor 1 g., glucose 5 g., sucrose 2 g., pH to 7.0, agar 20 g., distilled water 1 l.

Corn meal +salts agar. Coarse ground maize meal 50 g., tap water $1000 \mathrm{ml}$., steamed $30 \mathrm{~min}$. and filtered. To the filtrate were added $\mathrm{Na}_{2} \mathrm{HPO}_{4} \mathbf{1} \cdot 15 \mathrm{~g}$., $\mathrm{KH}_{2} \mathrm{PO}_{4}$ $0.25 \mathrm{~g}$., $\mathrm{KCl} 0 \cdot 2 \mathrm{~g}$., $\mathrm{MgSO}_{4} \cdot 7 \mathrm{H}_{2} \mathrm{O} 0.2 \mathrm{~g}$., agar $20 \mathrm{~g}$. and the volume adjusted to $1000 \mathrm{ml}$., pH 6.8.

Oatflour agar. Oatflour 25 g., $\mathrm{CaCO}_{3} 20$ g., glucose 5 g., distilled water 1 l., pH 6.8, agar $20 \mathrm{~g}$.

Photographs. Photomicrographs were taken using either a Watson 'Bactil 60' binocular microscope with a Watson Eyepiece Camera and Ilford Pan. F film or a trinocular American Optical 'Microstar' microscope with a $35 \mathrm{~mm}$. photography attachment and Kodak High Contrast Copy film. Electron photomicrographs were taken with an RCA EMU-3D electron microscope. Collodion films mounted on grids were touched onto 21 day cultures grown at $30^{\circ}$ on potato + carrot agar, the mycelium becoming attached to the collodion membrane.

\section{Examination of spore germination}

Spores, suspended in $\mathrm{pH} 7 \cdot 0$ phosphate buffer and filtered through fine nylon net, were diluted and spread on the surface of $1.8 \%$ water agar in Petri dishes. The plates were incubated at $30^{\circ}$ and periodically examined directly with the microscope for the appearance of germ tubes. The method of Lechevalier et al. (1961) was also used.

\section{RESULTS}

Description of Microellobosporia Cross, Lechavelier and Lechevalier gen.nov. (from ellobos-enclosed in a pod)

Morphology. Fine mycelium (about $1.0 \mu$ in diameter) which is differentiated into: (1) a substrate (primary) mycelium which grows into and forms a compact layer on top of the agar, (2) an aerial (secondary) mycelium which arises from the substrate mycelium and grows in the air away from the agar surface. The aerial hyphae bear sporangia on short sporangiophores. The sporangia contain a single row of nonmotile sporangiospores, usually numbering $2-5$. The substrate mycelium produces similar structures which were likewise interpreted as being sporangia containing a single row of non-motile spores. Three strains were isolated and these have been separated into two species.

Type species. Microellobosporia cinerea Cross, Lechevalier and Lechevalier sp.nov.

Substrate mycelium. About $1 \mu$ in diam. Hyphae long, branching, penetrating the agar medium and forming compact colonies which are at first colourless becoming 
pink to red-purple depending upon the medium and $\mathrm{pH}$ of that medium. Sporangia on short sporangiophores are borne on the surface of the agar and very likely in the agar (Pl. 1, fig. 3). Technical difficulties concerned with the staining of the sporangial wall inside the agar did not permit establishment of the sporangial nature of these sporogenic structures with absolute certainty. Photographs (Pl. 1, fig. 3) show a light aureole around the spores which might be caused by a sporangial wall. On some agar media, where the production of aerial mycelium is limited, the surface of the colonies are covered with sporangia.

Aerial mycelium. About $1 \mu$ in diam. Long-branching hyphae grow from the colony and also, to a lesser extent, from the substrate mycelium ramifying in the agar around the colony. Some autolysis occurs on a variety of media after lengthy incubation.

Sporangia. Sporangia appear singly and laterally on the aerial hyphae after 3-4 days incubation ( $\mathrm{Pl}$. 1, figs. 1, 2). Later they are borne in greater numbers and also occur terminally. When mature, the sporangia vary in length from 2 to $9 \mu$ and in diam. from 1.5 to $3 \cdot 6 \mu$ depending upon the number and size of the contained spores. Usually the sporangia contain 2 to 5 spores; single-spored sporangia occur infrequently and then most often on the short aerial hyphae growing from the substrate mycelium encircling the colony. Occasionally long sporangia containing 6 or 7 spores can be seen. Sporogenic structures borne on the substrate hyphae are associated with areas of colonial growth which appear somewhat darker in colour than neighbouring, non-sporogenic hyphae. The sporangial wall is thin and wrinkled and does not appear to bear any appendages (Pl. 1, figs. 4, 5 and 10). It originates from the apex of the sporangiophore which is swollen. The spores vary in size, even within a single sporangium, from 1.5 to $3.5 \mu$ (average $2.5 \mu$ ), and are round to oval. A short sporangiophore which tapers towards the main hypha is usually present and this can occasionally produce a lateral branch which matures into a sporangium (Pl. 1, fig. 2). Phase-contrast examination of the sporangia, borne on the substrate mycelium, suggests a structure similar to that of the aerial sporangia, though in this case the majority of the sporangia contain only two spores (Pl. 1, fig. 3). Mature spores are easily separated from one another on release from the sporangium, but can remain attached and germinate in pairs. During germination one to three germ tubes are produced which quickly show branching.

Sporangium formation. A lateral bud on a hypha grows to form a short lateral club-shaped initial structure. The contents divide up into spores which swell slightly to give the sporangium a beaded appearance. This process is illustrated for strain No. 3857 ( $\mathrm{Pl}$. 1, figs. 6-9). These sporangia, at first sight, resemble the chains of conidia produced by Waksmania and Micropolyspora. In some cases the tip of the sporangial wall can be seen, with the light microscope, projecting as a cap beyond the terminal spore. In water mounts stained with dilute methylene blue, the sporangial wall can be seen ruptured and liberating the contained spores (PI. 1, figs. 4 and 5).

Appearance on various media. Cultures were incubated in the dark at $30^{\circ}$ for 2 weeks. When first isolated the species showed good pigment production as described below. Repeated subculturing reduced the intensity of the pigments.

Czapek solution agar (Raper \& Thom, 1949). Excellent growth. Colonies large, convex, often with an apical depression and deep radial fissures. Reverse colours 


\section{4 \\ T. Cross, M. P. Lechevalier and H. Lechevaliter}

light brown to purple brown. Aerial mycelium slow in forming and then only thinly covering the colony, white to off white. Soluble pigment purple brown.

Synthetic agar (Lindenbein, 1952). Growth good, colonies pulvinate, smooth and entire, reverse colour bright red. Aerial mycelium thin and mealy, white. Both the colonies and soluble pigment show indicator properties: when flooded with dilute $\mathrm{NaOH}$ they become purplish pink, and with dilute $\mathrm{HCl}$ yellow to orangepink.

Inorganic salts + starch agar (Pridham et al. 1957). Growth good, colonies coloured pale pink brown. Aerial mycelium thin, cottony white to pale grey. Soluble pigment pale yellow.

Oatmeal agar (Küster, 1959). Growth good, reverse colour light grey brown becoming dark grey brown when lysis of the aerial mycelium occurs. Aerial mycelium thin, light grey, with abundant sporangia. No soluble pigment.

Oatflour agar. Excellent growth, very large convex colonies (up to $15 \mathrm{~mm}$. in diameter), bright red in colour. Aerial mycelium pale grey to medium grey. Soluble pigment red to wine red.

Soya+glucose agar. Growth moderate, colonies pale brown to light purple brown, aerial mycelium sparse, light grey. Colonies lacking aerial mycelium show abundant production of sporangia on their surface. No soluble pigment.

Rice extract agar (Lechevalier \& Lechevalier, 1957). Growth moderate, colonies pale brown to pale purple. Aerial mycelium pale grey. Little soluble pigment, pale purple.

Potato + carrot agar. Growth good, colonies umbonate with undulate margin. Reverse colour brown to purple brown. Aerial mycelium good, velvety, pale grey with abundant sporangia. Soluble pigment slight, red orange to red brown.

Corn meal + salts agar. Growth good, colonies pulvinate, smooth, reverse colour pale pink. Aerial mycelium thin, pale grey, abundant sporangia. Soluble pigment none to very pale pink.

Dextrose + tryptone agar (Burkholder, Sun, Anderson \& Ehrlich, 1955). Growth very good, colonies pulvinate with central depression and few radial fissures. Reverse colour reddish orange to purple red. Aerial mycelium variable, good on some colonies but only sparse on others, white. Soluble pigment strong reddish orange.

$X S M$ agar. Growth very good, reverse colony colour pale purple brown to strong brown purple. Aerial mycelium good, velvety, pale grey, some lysis. Soluble pigment purple brown.

Glycerol +asparagine agar (Burkholder et al. 1955). Growth excellent, large colonies with central depression and radial fissures, pink to red in colour. Abundant sporangia produced on substrate mycelium. Aerial mycelium moderate, light grey. Soluble pigment pink.

Yeast extract agar (Waksman, 1950). Pink to red, moist growth, wrinkled. No aerial hyphae.

Sabouraud's medium-with $2 \%$ glucose (Segretain, Drouhet \& Mariat, 1958). Excellent pink to reddish, moist and wrinkled growth. No aerial hyphae.

Defined medium (Lechevalier et al. 1961). Excellent light orange tan vegetative growth. Soluble yellow pigment. No aerial mycelium. 
Beef extract + starch agar (Society of American Bacteriologists, 1957). Deep rosepink vegetative growth. Soluble brownish pigment; no aerial mycelium.

Potato plug. Pink to rose convoluted growth. No aerial hyphae.

Production of melanoid pigment. No melanoid pigment was produced when the isolate was grown on tyrosine + casein + nitrate agar (Menzies \& Dade, 1959), peptone +iron + yeast extract agar ('Tresner \& Danga, 1958) or the cystine-bismuth agar of Hunter \& Crecelius (1938).

Gelatine hydrolysis (Society of American Bacteriologists, 1957). Gelatine was hydrolysed but not as strongly as by the two strains of $M$. flavea.

Starch hydrolysis (Society of American Bacteriologists, 1957). Starch was strongly hydrolysed.

Nitrate reduction (Society of American Bacteriologists, 1957). No nitrite was detected.

Litmus milk (Difco Manual, 1953). Growth took place with peptonization and alkalinization but no coagulation.

Effect of $p H$ and temperature on growth. The effect of temperature on growth was investigated by incubating inoculated slants of potato + carrot agar at $22^{\circ}, 28^{\circ}, 37^{\circ}$ and $47^{\circ}$. Growth was good at the three lower temperatures and null at $47^{\circ}$. In addition, the effects of $\mathrm{pH}$ and temperature on growth of the isolate were simultaneously investigated using the buffered glucose + asparagine medium of Taber (1960). The results are given in Table 1.

Table 1. Growth of Microellobosporia cinerea on glucose + asparagine agar buffered at different $p H$ levels and incubated at different temperatures

$\begin{array}{ccccccc}\begin{array}{c}\text { Temp. } \\ \left({ }^{\circ} \mathbf{C} .\right)\end{array} & \overbrace{8.5} & 6.9 & 6.7 & 6.6 & 6.3 & 6.1 \\ 42 & - & - & - & - & - & - \\ 37 & - & - & - & - & - & - \\ 30 & +++ & +++ & +++ & +++ & +++ & +++ \\ 25 & +++ & +++ & ++ & + & + & + \\ 22 & - & - & - & - & - & - \\ - \text { No growth, + little growth, }++ \text { moderate growth, }+++ \text { good growth. }\end{array}$

Growth occurs in the temperature range $25^{\circ}-30^{\circ}$, with the optimum temperature for growth and sporangium production being about $30^{\circ}$. The culture appears more sensitive to an acid $\mathrm{pH}$ when incubated at a lower temperature. This result was interesting for it suggested that the $\mathrm{pH}$ sensitivity of a culture could be influenced by the incubation temperature and that Taber's findings on the acid sensitivity of actinomycetes might have to be modified if a range of temperatures were used in the study.

Antibiotic properties. Microellobosporia cinerea 3855 was tested for antibiotic activity by cross-streak test on six different solid media. Zones of inhibition were produced with Gram-positive bacteria and a Mycobacterium, no inhibition of Gramnegative bacteria and fungi was observed. Shake-flask cultures showed weak activity against Staphylococcus aureus but no activity against a range of Gramnegative bacteria, yeasts and fungi using a cup-plate assay method. 
Sensitivity to antibiotics. On nutrient agar with glucose (Lechevalier et al. 1961), at pH 6.3, the growth of the culture was not affected by $50 \mu \mathrm{g} . / \mathrm{ml}$. of either amphotericin B or pimaricin. Growth was completely inhibited by $30 \mu \mathrm{g}$. chloramphenicol

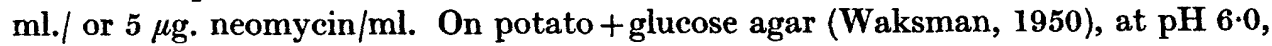
the antifungal antibiotics were also without effect, whereas $20 \mu \mathrm{g}$. chloramphenicol $/ \mathrm{ml}$. and $5 \mu \mathrm{g}$. neomycin $/ \mathrm{ml}$. were completely inhibitory.

Source. Isolated from a soil sample collected at Princess Margaret Glacis, Pilta, Malta.

Description of Microellobosporia flavea, Cross, Lechevalier and Lechevalier sp.nov.

The two strains of this species showed the same microscopical properties previously described for the type species. The aerial mycelium was pale to light grey, and, whereas the type species was a pinkish organism, $M$. flavea produced a yellow soluble pigment, the colour of which was not affected by $\mathrm{pH}$.

Appearance on various media. Cultures were incubated in the dark at 30 or $37^{\circ}$ for 2 weeks. This was due to differences in the temperature optima of the two strains. Isolate 3857 grew best at $30^{\circ}$, whereas 3858 sporulated more abundantly at $37^{\circ}$. Both strains grew well at the same temperatures as the strain of the type species. The two strains of $M$. flavea, like that of the type species vigorously hydrolysed gelatine and starch. On litmus milk and nitrate medium, there was also no difference in the behaviour of the representatives of the two species.

Czapek solution agar. Good, off-white, smooth, leathery growth. No aerial hyphae. 3857 had a slight orange tint; 3858 a slight tan tint.

Synthetic agar (Lindenbein). Growth good, reverse colony colour orange. Aerial mycelium white, abundant (3857) or scant and powdery (3858). Soluble pigment orange yellow.

Defined medium (Lechevalier). Yellow-cream, convoluted, vegetative growth. No aerial mycelium. No soluble pigment.

Corn meal + salts agar. Good, off white vegetative growth. Aerial mycelium white to ash grey, thin (3857) or good (3858). No soluble pigment.

Beef extract + starch agar. Colourless vegetative growth; no soluble pigment. No aerial hyphae.

Yeast extract agar. Light tan, moist, wrinkled growth. No aerial hyphae.

Potato plug. Convoluted growth without aerial hyphae. 3857 was brownishcream coloured whereas 3858 was cream coloured without a brownish tint.

Potato + carrot agar. Off-white vegetative mycelium, reverse of culture greenish. Abundant woolly grey aerial mycelium (3857) or scanty grey aerial mycelium (3858). Abundant sporangial formation.

Rice extract agar. 3857: off-white vegetative growth; light charcoal grey aerial mycelium; no soluble pigment. 3858: white vegetative growth; sparse white aerial mycelium; soluble yellow pigment.

Pablum agar (Lechevalier \& Lechevalier, 1957). White to tan vegetative growth; light charcoal grey aerial mycelium. Soluble yellow pigment. Abundant formation of sporangia.

Sabouraud's medium with glucose. Moist wrinkled light tan vegetative mycelium. No aerial hyphae. 
Antibiotic properties. By cross-streak test, strain $\mathbf{3 8 5 7}$ showed no antibiotic activity and strain $\mathbf{3 8 5 8}$ was only faintly active against Gram-positive bacteria.

Sensitivity to antibiotics. The two strains of $M$. flavea were resistant and sensitive to the same antibiotics as $M$. cinerea. They were somewhat more sensitive to the action of the antibacterial antibiotics than the representative of type species.

Source. Strain $\mathbf{3 8 5 7}$ was isolated from a soil sample collected at the base of a tree in Orly Airport, France, and strain 3858 from grassland soil collected in Les Andelys, Eure, France.

\section{DISCUSSION}

The characteristic production of sporangia containing few linearly arranged spores, on both the aerial and substrate mycelium in these cultures differentiates them from previously described species and justifies the erection of a new genus in the family Actinoplanaceae Couch, 1955. As a consequence, the following revision of the existing key to the family is proposed:

1. Aerial mycelium usually not formed; conidia lacking; sporangia, usually spherical, large $(8-22 \mu)$, containing motile spores.

Actinoplanes Couch, 1950

2. Aerial mycelium abundant; conidia as well as sporangia are formed in some species; sporangia spherical, large $(7-19 \mu)$ containing non-motile spores.

Streptosporangium Couch, 1955

3. Aerial mycelium abundant; conidia lacking; small sporangia, produced on both substrate and aerial mycelium, club shaped $(2-9 \mu \times \mathbf{1} \cdot 5-3 \cdot 6 \mu)$ containing a short single row of non-motile spores.

Microellobosporia. gen.nov.

Spore formation can be seen to take place inside the wall of the initial sporangial structures and the development of the spores and their relation to the wall appears quite different from that described by Glauert \& Hopwood (1961) for Streptomyces violaceoruber. The sporangial wall originates from the swollen tip of the sporangiophore and remains intact and separate from the spores during development. After spore release the sporangial wall persists as an open sac. It would be tempting to extend the relationships suggested by Hesseltine (1960) between the genera Actinoplanes and Streptosporangium on the one hand, and Streptomyces on the other, to include Microellobosporia. Here the spores are few in number, they are aligned in a single straight row and exceed somewhat the spore size typical of the Streptomyces. But until more detailed work on the walls of the mycelium and sporangium, and their relation to the developing spore have been carried out it would be unwise at this stage to propose any evolutionary relationships.

The fact that two related strains (Nos. 3857 and 3858) were isolated quite soon after the initial isolation of Microellobosporia cinerea would suggest that members of this genus are not rare soil-inhabiting organisms. They are not exacting in their nutritional or temperature requirements, and can be isolated readily using media conventionally used for the isolation of Streptomyces. When growing on agar they closely resemble Streptomyces in gross appearance and one must assume they have been isolated in the past and mistaken for these organisms. 
The authors wish to thank Miss Pauline E. Holbert and Mrs Martha Rancourt for the electron photomicrograph. This work was supported in part by grant G-9694 from the National Science Foundation. Part of this work was carried out in the Laboratories of Mycology of the Pasteur Institute of Paris while one of us (H.L.) was the holder of the U.S. Public Health Service Special Fellowship No. E.F. 13,313.

\section{REFERENCES}

Bergey's Manual of Determinative Bacteriology (1957). 7th ed., ed. by R. S. Breed, E. G. D. Murray \& N. R. Smith. Baltimore: The Williams and Wilkins Co.

Burkholder, P. R., Sun, S. H., Anderson, L. E. \& Ehrlich, J. (1955). The identity of viomycin producing cultures of Streptomyces. Bull. Torrey Bot. Club. 82, 108.

Difco Manual of Dehydrated Culture Media and Reagents for Microbiological and Clinical Laboratory Procedures (1953). 9th ed. Detroit: Difco Laboratories.

Glauert, A. M. \& Hopwood, D. A. (1961). The fine structure of Streptomyces violaceoruber (S. coelicolor). III. The walls of the mycelium and spores. J. biophys. biochem. Cytol. 10, 505.

Hesseltine, C. W. (1960). Relationships of the Actinomycetales. Mycologia, 52, 460 .

Hunter, C. A. \& Creceluus, A. G. (1938). Hydrogen sulphide studies. I. Detection of hydrogen sulphide in cultures. J. Bact. 35, 185.

Karling, J. S. (1954). An unusual Keratinophilic microorganism. Proc. Indiana Acad. Sci. 63, 83.

Krassilnikov, N. A. (1949). Guide to the Identification of Bacteria and Actinomycetes. English edition edited by J. B. Routien. New York: Chas. Pfizer and Co.

KüstER, E. (1959). Outline of a comparative study of criteria used in characterization of the Actinomycetes. Int. Bull. bact. Nomen. 9, 97.

Lechevalier, H. A., Solotorovsky, M. \& McDurmont, C. I. (1961). A new genus of the Actinomycetales: Micropolyspora gen.nov. J. gen. Microbiol. 26, 11.

Lechevalier, M. P. \& Lechevalier, H. A. (1957). A new genus of Actinomycetales: Waksmania gen.nov. J. gen. Microbiol. 17, 104.

Lindenbein, W. (1952). Uber einige chemisch interessante Aktinomyceten Stämme und ihre Klassifizierung. Arch. Mikrobiol. 17, 361.

Menzies, J. D. \& DaDe, C. E. (1959). A selective indicator medium for isolating Streptomyces scabies from potato tubers or soil. Phytopathol. 49, 457.

Pridiam, T. G., Andersen, P., Foley, C., Lindenfelser, L. A., Hesseltine, C. W. \& BENEDict, R. G. (1957). A selection of media for maintenance and taxonomic study of Streptomyces. Antibiotics Ann., 1956/57, p. 947.

Raper, K. B. \& Thom, C. (1949). Manual of the Penicillia, p. 64. Baltimore: The Williams and Wilkins Co.

Rothwell, F. M. (1957). A further study of Karling's Keratinophilic organism. Mycologia, 49, 68.

Segretain, G., Drouhet, E. \& Mariat, F. (1958). Diagnostic de Laboratoire en Mycologie Médicale. St.-Mandé, Seine: Editions de la Tourelle.

Society of American Bacteriologists (1957). Manual of Microbiological Methods. New York: McGraw-Hill, Inc.

TABER, W. A. (1960). Evidence for the existence of acid-sensitive actinomycetes in soil. Canad. J. Microbiol. 6, 503.

Tresner, H. D. \& Danga, F. (1958). Hydrogen sulphide production by Streptomyces as a criterion for species differentiation. J. Bact. 76, 239.

Vernon, T. R. (1955). Spore formation in the genus Streptomyces. Nature, Lond. 176, 935.

Waksman, S. A. (1950). The Actinomycetes-their Nature, Occurrence, Activities and Importance. Waltham, Mass.: Chronica Botanica Co. 



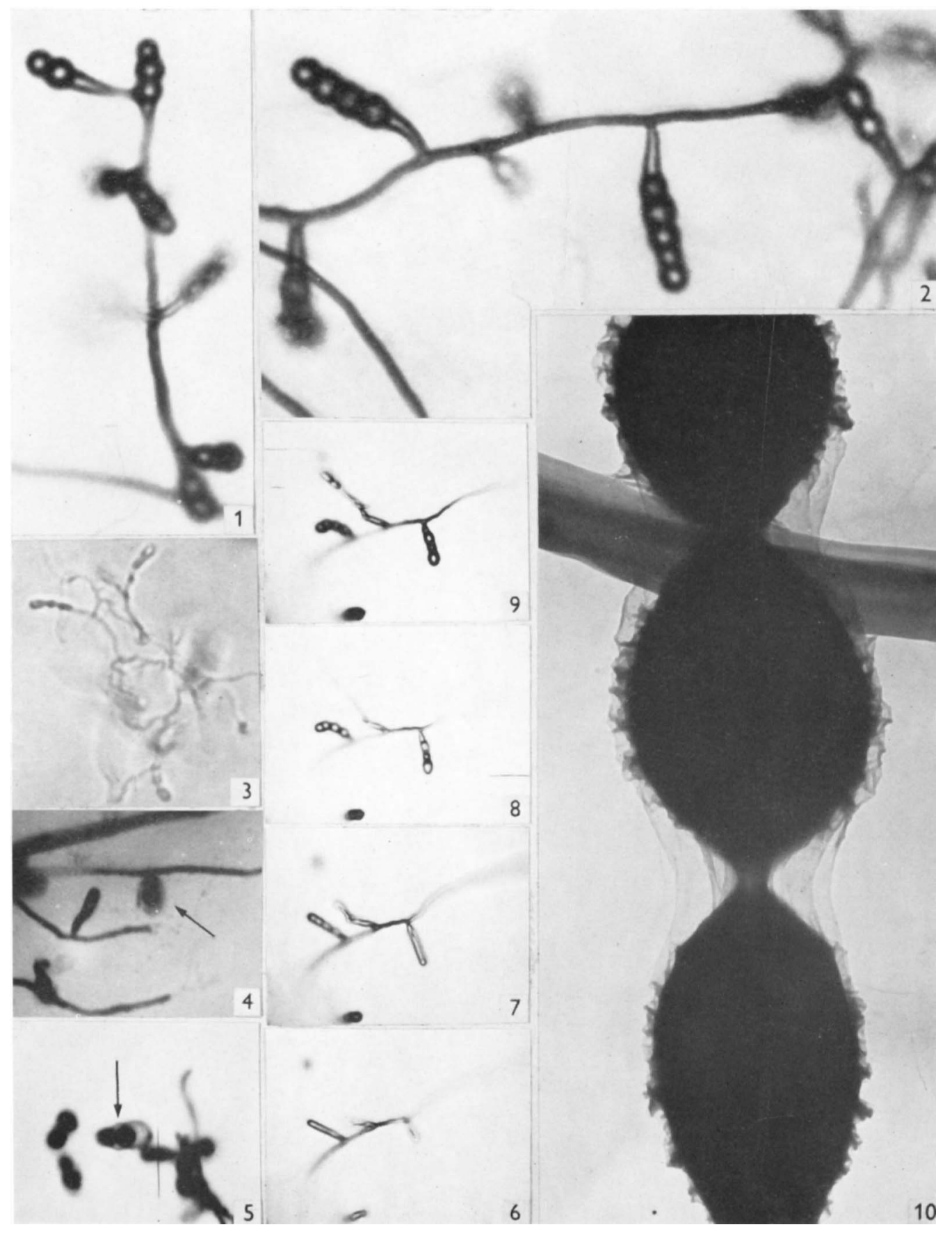

T. CROSS, M. P. LECHEVALIER AND H. LECHEVALIER 


\section{EXPLANATION OF PLATE 1}

Fig. 1. M. cinerea 3855; mature sporangia on aerial mycelium (corn meal +salts agar, 7-day culture). $\times 1400$.

Fig. 2. M. cinerea 3855 ; aerial mycelium showing proliferation of lateral sporangiophore from base of a sporangium (potato + carrot agar, 10-day culture). $\times 1400$.

Fig. 3. M. cinerea 3855 ; chains of spores on substrate mycelium seen $100 \mu$ below the surface of the agar (potato + carrot agar, 10-day culture). $\times 940$.

Fig. 4. M. flavea 3858 ; ruptured sporangium from aerial mycelium, stained with methylene blue; note sporangial wall. $\times 2500$.

Fig. 5. M. flavea 3857; disruptured sporangia from aerial mycelium, stained with methylene blue; sporangial wall is easily seen, open as if to permit release of spores. $\times \mathbf{2 5 0 0}$.

Fig. 6. M. flavea 3857; aerial mycelium showing growing lateral club-shaped structure (potato + carrot agar, 8 days). $\times \mathbf{5 4 0}$.

Fig. 7. Same culture, same place, half a day later; sporangiospores are forming in the left clubshaped structure. $\times \mathbf{5 4 0}$.

Fig. 8. Same culture, same place, 9 days; sporangiospores have been formed during the night inside the right branch; the left sporangium is fully formed. $\times \mathbf{5 4 0}$.

Fig. 9. Same culture, same place, half a day later; the right sporangium is fully formed; two spores have been formed inside the tip of the middle branch. $\times 540$.

Fig. 10. M. flavea 3857 ; electron microphotograph of part of a sporangium (potato + carrot agar, 21 days). $\times 23,000$. 